\title{
Diagnosis of the Relationship between Dust Storms over the Sahara Desert and Dust Deposit or Coloured Rain in the South Balkans
}

\author{
N. G. Prezerakos, A. G. Paliatsos, and K. V. Koukouletsos \\ General Department of Mathematics, Technological Education Institute of Piraeus, 250 Thivon and P. Ralli, 12244 Athens, Greece \\ Correspondence should be addressed to A. G. Paliatsos, agpal@in.teipir.gr
}

Received 1 December 2009; Accepted 19 July 2010

Academic Editor: Harry D. Kambezidis

Copyright ( $) 2010$ N. G. Prezerakos et al. This is an open access article distributed under the Creative Commons Attribution License, which permits unrestricted use, distribution, and reproduction in any medium, provided the original work is properly cited.

The main objects of study in this paper are the synoptic scale atmospheric circulation systems associated with the rather frequent phenomenon of coloured rain and the very rare phenomenon of dust or sand deposits from a Saharan sandstorm triggered by a developing strong depression. Analysis of two such cases revealed that two days before the occurrence of the coloured rain or the dust deposits over Greece a sand storm appeared over the north-western Sahara desert. The flow in the entire troposphere is southerly/south-westerly with an upward vertical motion regime. If the atmospheric conditions over Greece favour rain then this rain contains a part of the dust cloud while the rest is drawn away downstream adopting a light yellow colour. In cases where the atmospheric circulation on the route of the dust cloud trajectories is not intensively anticyclonic dust deposits can occur on the surface long far from the region of the dust origin. Such was the case on 4th April, 1988, when significant synoptic-scale subsidence occurred over Italy and towards Greece. The upper air data, in the form of synoptic maps, illustrate in detail the synoptic-scale atmospheric circulations associated with the emission-transport-deposition and confirm the transportation of dust particles.

\section{Introduction}

The phenomenon of coloured rain over the South Balkans and, in particular, over Greece occurs rather frequently, being associated with the appearance of Sahara or Atlas Mountains depressions [1-3]. On the other hand a significant easily visible, dust deposit upon Greece, coming from North Africa, is a very rare phenomenon occurring only once within the last twenty years on 4 April 1988 in north Greece. Also on 17 April 2005 the city of Athens was enveloped in a thick dust cloud. The dust cloud was not a localised event over Athens, but it was part of a synoptic-scale dust transport from Africa [4]. This event over Athens seems to be a little bit different from the other one, on 4th April 1988 in Thessalonica, studied here, because the dust was concentrated in the boundary layer with very little dry deposit on surface reducing dramatically the visibility. Of course coloured rain and/or dust deposits occur also in other European countries which are further north than Greece, for example, United Kingdom [5, 6], Spain [7], and generally Europe [8]. Also the transport and deposition of African dust is known to affect distant regions in the North Atlantic as far away as the Caribbean Islands $[9,10]$. Something similar occurs for the East Asian dust that is transported and deposited to a long distance towards the East as far as Hawaii [11-13]. Also Danielsen [14] investigated the development of severe storms above Texas as a dust source in the early 1970s. Finally, an intense dust storm over Greece has recently been studied by Kaskaoutis et al. [15].

Although many papers that deal with monitoring and predicting Saharan dust transporting northwards appeared after mid-90s when dispersion models were developed and very advanced sensors were put on meteorological satellites $[4,13,16-23]$, few papers before mid-90s that deal with case studies of the coloured rain phenomenon [1, 3, 24, 25] and one paper which deals with the phenomenon of dust or sand dry deposit on north Greece [26] have revealed the type of synoptic-scale atmospheric circulation which 
is associated with coloured rain or dry dust deposit over Greece. The dominant feature of this type of atmospheric circulation is a southerly to south-westerly flow through the entire troposphere extending from the North Sahara as far as the Balkans.

The whole process starts with the development of a North African depression resulting in a dust storm. This African depression is initiated by an upper-level trough or $\mathrm{PV}$ anomaly which occurs on the polar front jet (PFJ), when it overlies a heat low. Alternatively it is initiated by low-level baroclinicity southeast of the Atlas Mountains just north or beneath the Subtropical jet stream (STJ) [27] when there is an interaction between the PFJ and the STJ because the PFJ has moved south as far as North Africa to approach the STJ closely. The suggestion that the interaction of the two jets can initiate and develop the depression due to the increase of hydrodynamic instability which needs more research as Karein [28] based on Defant's theory [29] has studied only one case in the eastern Mediterranean. Also Prezerakos et al. [30] have revealed the role of the interaction of these two jets on the rejuvenation of depression over the eastern Mediterranean. The option that these North African depressions can be treated as normal baroclinic waves $[27,31,32]$ associated with the PFJ PV anomalies typically occurring in the winter and the spring due to the approaching of the PFJ over North Africa seems to be more satisfactory.

The rising dust embedded in the south-westerly and upward synoptic-scale vertical motion tropospheric flow drifts over large distances together with significant warm air advection reaching Greece and the South Balkans. This dust is responsible for hazy weather conditions for several days over Greece.

Sometimes the rising dust forms a dust cloud stirring up to a few tens or hundreds of meters with the thinner dust grains ascending to greater heights, for example, 3$4 \mathrm{~km}$ or more $[2,6,25]$. This dust cloud and the Sahara depression move together, being steered by the polar or subtropical jet stream but mainly in the lower half of the tropospheric flow. Some of the dust grains, being in an atmospheric environment of increased humidity, become condensation nuclei falling on the ground as raindrops, when ascending air motions dominate the region. Also, the rest of the dust grains are mixed into the raindrops which thus appear coloured. This is shown clearly when the rain droplets evaporate. In such a case numerous spots cover every surface, especially cars, in the open air. These spots are approximately round, with a diameter of about $0.1-0.2 \mathrm{~cm}$ and with a light yellow colour consisting of extremely fine-grained dust [25]. When the drifting dust cloud is embedded in an intense but dry upper tropospheric anticyclonic flow leading to strong synoptic-scale descending motion or in an ordinary (not small scale) synoptic-scale upward motion, then it is accelerated due to gravity to fall out as a thick deposit on the earth surface looking like desert sand (particles $<20 \mu \mathrm{m}$ ).

It follows from the previous paragraphs that the dust transport toward the South Balkans occurs when intensive cyclogenesis develops in Northwest Africa (the source region) and at the same time the dominant feature of the regional atmospheric circulation is a southerly to southwesterly flow throughout the entire troposphere from the Northwest Sahara as far as the Balkans. This combination is a frequent event in winter and especially in spring $[2,3,18$, $33,34]$. As a result spring is the most likely season for the occurrence of coloured rain or dust deposit over the South Balkans $[18,33,34]$.

Previous attempts have been made by other Greek scientists $[1,24-26]$ to study the synoptic-scale atmospheric circulation using early satellite images associated with cases of coloured rain or/and dust deposit upon the South Balkans. This work will focus on the study of the correlation between sand storms over North Africa and coloured rain and/or dust deposit upon Greece. We will base our study mainly on high resolution satellite images but not so advanced as the nowadays ones and air trajectories. These are effective tools to diagnose and forecast the course of drifting airborne particles and pollutants within the atmosphere. This paper can then be used as a standard for verifying the results of physical models of dust emission $[19,35]$ or forecast numerical models of dust suspension, transport, and deposition. Such forecast numerical models are already in operation [16$18,21-23,36-38]$ with reliable results in a number of tests.

A part of the data used in this paper constituted a presentation delivered in an international symposium held in Damascus, Syrian Arab Republic in November 1997 [39]. At that presentation, the justification of the dry dust deposit in the morning of 4th April 1988 on surface in Thessalonica a place with upward synoptic-scale vertical air motion, that time, appeared highly questionable. Then this justification has been under continuing consideration with more data added intending a more reasonable explanation to be formatted.

The publication of this paper in a worldwide circulated journal, as the "Advances in Meteorology", provides the trigger effect to other researchers to investigate more in depth this case for an absolutely clear justification.

This paper is organized as follows. Section 2 describes the dataset and methodology employed in this study. In Section 3 there is an analysis and discussion of the 27 th March 1992 case of coloured rain upon Greece. Section 4 consists of a further brief analysis and discussion of the 4th April 1988 case of significant dust deposit upon Thessalonica, north Greece. The conclusions are summarized and discussed in Section 5.

\section{Data and Methodology}

The majority of data used in this investigation comes from the ECMWF archived operational initialized analyses using a resolution of $1.5^{\circ} \times 1.5^{\circ}$ along latitude and longitude circles. More specifically, these data are geopotential height, temperature, and horizontal winds at 900, 850, 700, 500, and $300 \mathrm{hpa}$ isobaric levels, which depict the course of the drifting dust toward the South Balkans. Also, data of mean sea level atmospheric pressure and vertical velocities at 900, 850,700 , and $500 \mathrm{hpa}$ isobaric levels was obtained from the same source in order to show the dust source and deposit places. 


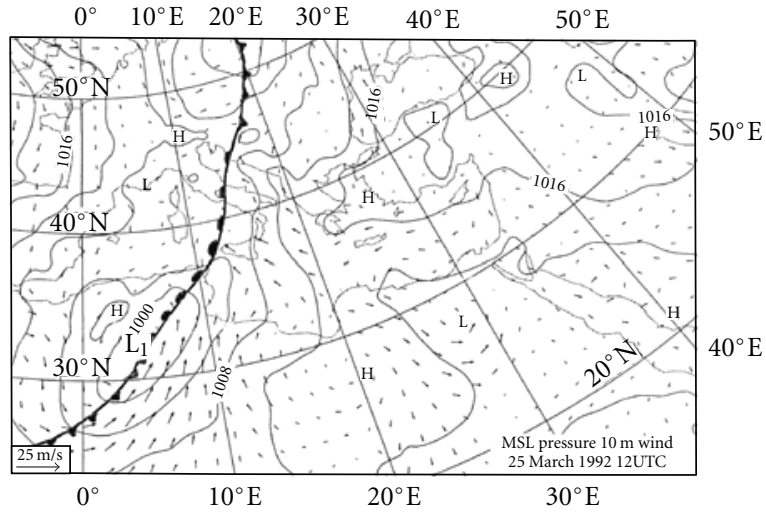

Figure 1: Mean sea level objective pressure analysis at 12:00 UTC on 25 March 1992. Isobars: every 4 hpa. The fronts are denoted by the conventional symbols and are transferred from the Hellenic National Meteorological Center respective subjective analysis. The scale of the wind velocity is at the lower left corner.

To facilitate the study and understand the course of the drifting dust in the atmosphere and its final arrival, 5-day backward air trajectories were calculated for Athens and Thessalonica which arrived at 12:00 UTC on 27 March 1992 (the day on which coloured rain occurred) for four different heights (below 900, 850, 700, and $500 \mathrm{hpa}$ ). The trajectories were calculated using the trajectory model of the Deutscher Wetterdienst (DWD) based on the results of the DWD global model (here 6 hourly analyses of the spectral parameters of divergence and potential vorticity were transformed to give horizontal winds and surface pressure on a global Gaussian grid). Additional information on the DWD trajectory model can be found in the paper by Kottmeier and Fay [40].

As there was no archive before 1990 it was not possible to run the DWD global model for calculating trajectories for the case of dust deposit upon the Thessalonica region in the morning on 4 April 1988. To compute trajectories for this case we used Seijo Kruinzinga's program, which is the operational one in ECMWF, and the ECMWF Reanalysis (ERA 40) as input. Nowadays this program can be used freely for research purposes and internal purposes of all the ECMWF member states. The program can be used for computing three-dimensional forward as well as backward trajectories using wind analyses and wind forecasts from the ECMWF model. In order to have three-dimensional trajectories all three wind components are used.

The computed trajectories are 5-day backward air-parcel trajectories originating in Thessalonica on 4th April 1988 at 00:00 UTC in 900, 850, 700, 500, and 300 hpa heights. For these studies only the first 2 days of the back trajectories are used. Also images from NOAA AVHRR (Advanced Very High Resolution Radiometer) being adopted from météoFrance archives are used for the case on 25-27 March 1992 to confirm the origin and tracking of the dust cloud. The satellite images for the 1988 case are coming from University of Dundee archives.

According to the annual international WMO (World Meteorological Organization) verification of numerical weather prediction model results, the ECMWF model and the GM of DWD on average show a similar performance and rank amongst the best NWP models worldwide [41]. As the quality of the wind fields determined by the two models is not different, the trajectories produced by both models appear to have the same efficacy since they depend on the quality of the wind fields. The main trajectory error sources come from the wind errors, which are caused directly by incorrect observations, model forecasts, and analyses and also by spatial and temporal interpolation of the wind fields to the trajectory positions.

However, the use of trajectories based on analyses associated with AVHRR images and synoptic atmospheric circulation patterns is the best way to describe the path of infinitesimal air parcels through the atmosphere, and they are widely used for evaluating measurements and verifying forecast trajectory models.

\section{Analysis and Discussion of the 27th March 1992 Case of Coloured Rain over Greece}

3.1. Synoptic-Scale Atmospheric Patterns. At about 12:00 UTC on 27 March 1992, a significant amount of coloured rain (about $30 \mathrm{~mm}$ from 06:00 to 18:00 UTC), occurred in Athens (Athens Observatory, $37.97^{\circ} \mathrm{N}, 23.72^{\circ} \mathrm{E}$ and Helleniko WM016716). Two days earlier, that is, at 12:00 UTC on 25 March 1992 two depressions were developing over North Africa. One vigorous depression was centred south of the Atlas Mountains extending north-eastwards as far as Sicily and eastwards as far as the borders between Tunisia and Libya. The other one, much weaker, was centred over Egypt (Figure 1). These two depressions were separated by a weakening high-pressure system. Strong winds up to $30 \mathrm{kn}$ accompanied the depressions in the rear and ahead of the cold front associated with the depression. These increased due to the unstable thermal stratification and associated intense vertical mixing producing downward transport of high momentum to the surface, and this resulted in the Sahara sand rising into suspension causing dust storms. It is worthwhile recalling that only dust particles smaller than $20 \mu \mathrm{m}$ can be lifted up into the atmosphere for days and experience long range transport whereas sand particles greater than $20 \mu \mathrm{m}$ result in sandblasting and creeping sand dunes.

Synoptic-scale ascending motion can be seen over the region of the Atlas depression (Figures 2(a), 2(b), and 2(c)) at 850,700 , and $500 \mathrm{hpa}$ isobaric levels especially along the front. The maximum values are $-0.6,-0.5$, and $-0.6 \mathrm{Pas}^{-1}$ at 850,700 , and $500 \mathrm{hpa}$ correspondingly, thus helping the vertical mixing for transferring dust upwards. The airflow near the surface, being between the Atlas Mountains depression and the high over Libya, is from the south (Figure 1).

Also the tropospheric flow at 850,700 , and $500 \mathrm{hpa}$ (Figures 3(a), 3(b), and 3(c)) in the vicinity of the Atlas Mountains depression is south-westerly carrying the dust north-eastwards. This low level warm air is moving polewards and gradually rising to reach the level of $700 \mathrm{hpa}$ or 

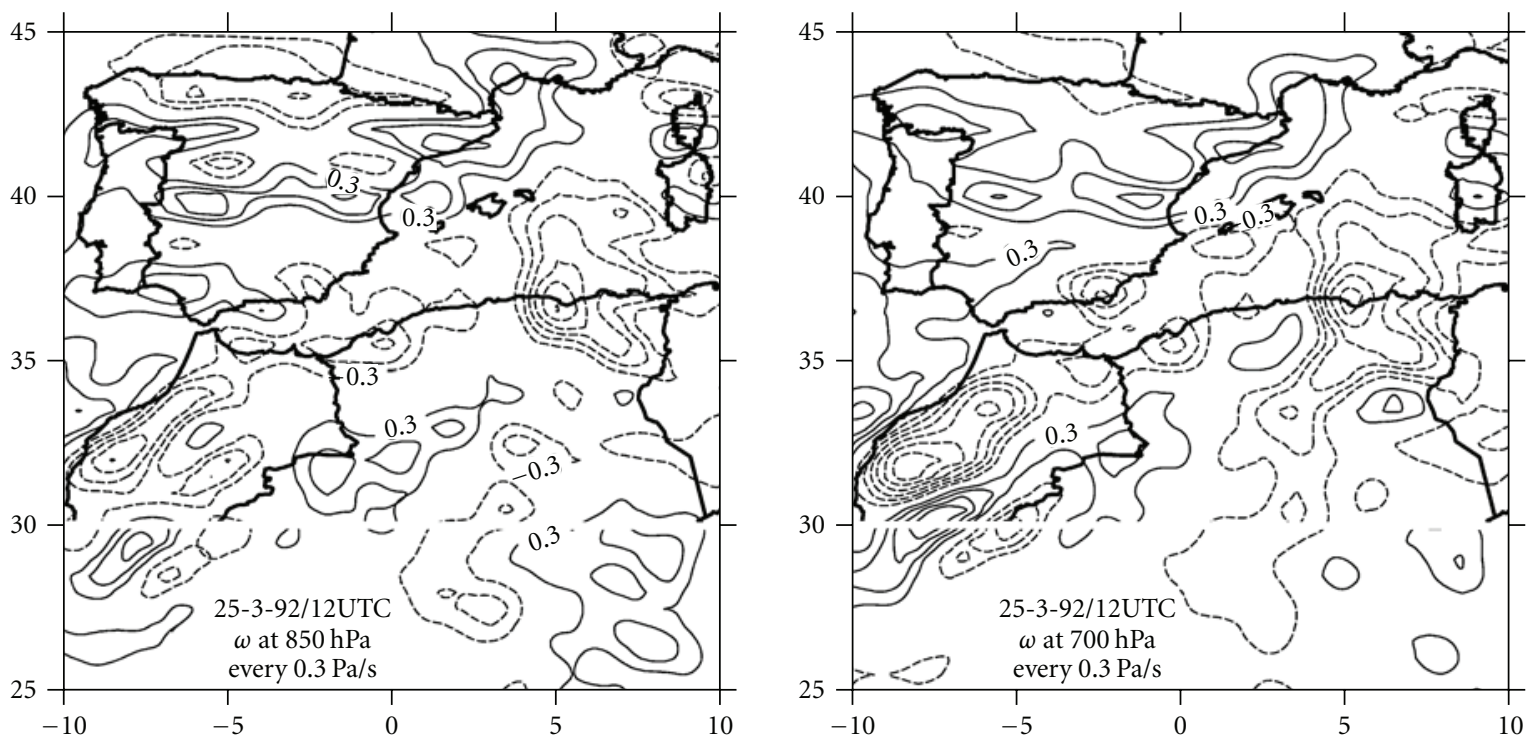

(a)

(b)

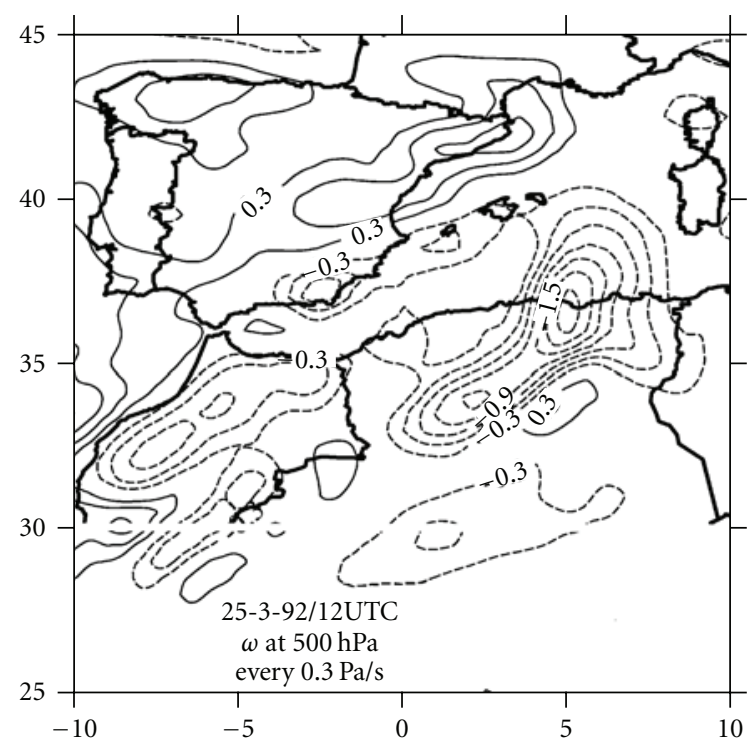

(c)

Figure 2: Vertical velocity fields at 12:00 UTC on 25 March 1992 at, (a) 850 hpa, (b) 700 hpa, and (c) 500 hpa. Isopleths of vertical velocity: every $0.3 \mathrm{Pas}^{-1}$ (dash: upward; continuous: downward).

higher over Greece $48 \mathrm{~h}$ later. The flow at the same levels over Egypt is westerly/south-westerly steering the Egyptian depression eastwards. A quantitative approach regarding the location and activity of dust sources in the Sahara can be found in the literature, for example, $[19,35,38,42-44]$.

At $300 \mathrm{hpa}$ (Figure 4) at the same time there is an interaction between the polar and subtropical jet streams southwest of the Atlas Mountains. It may be hypothesised that this interaction causes an increase in the hydrodynamic instability [28] over this region or strengthens the synopticscale upward motion [30], which itself may lead to the development of the vigorous depression $\mathrm{L}_{1}$ as shown in
Figure 1. These views are in need of more research. Indeed, following Petterssen's [45] ideas, we can suggest that the Atlas depression $\mathrm{L}_{1}$ was initiated when the region of positive absolute vorticity advection ahead of the 500 or $300 \mathrm{hpa}$ trough $\mathrm{T}_{1}$ (Figure 4) became superimposed over the shallow frontal surface shown in Figure 1. This suggestion is backed up by the narrow zone of potential temperature isopleths in this region (Figure 3(a)). At 12:00 UTC on March 251992 depression $\mathrm{L}_{1}$ was developing, while the head of the region of positive absolute vorticity advection ahead of trough $\mathrm{T}_{2}$ (Figure 4) results in barometric tendencies becoming negative at the surface and a well-developed depression $\mathrm{L}_{2}$ 


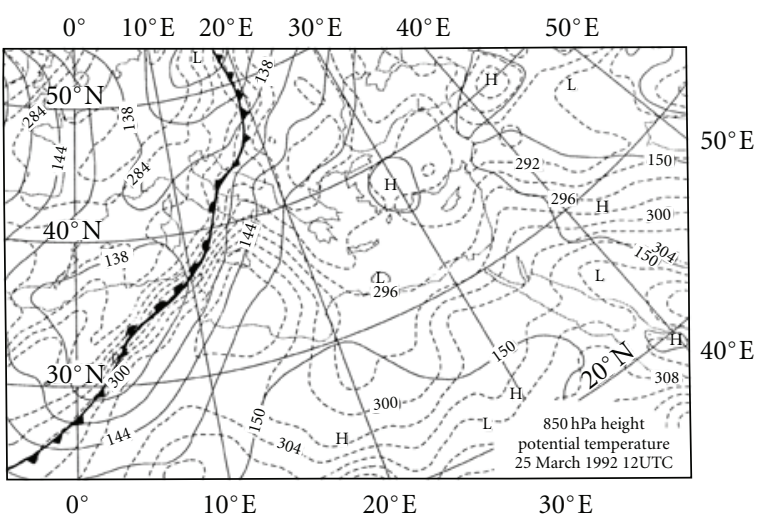

(a)

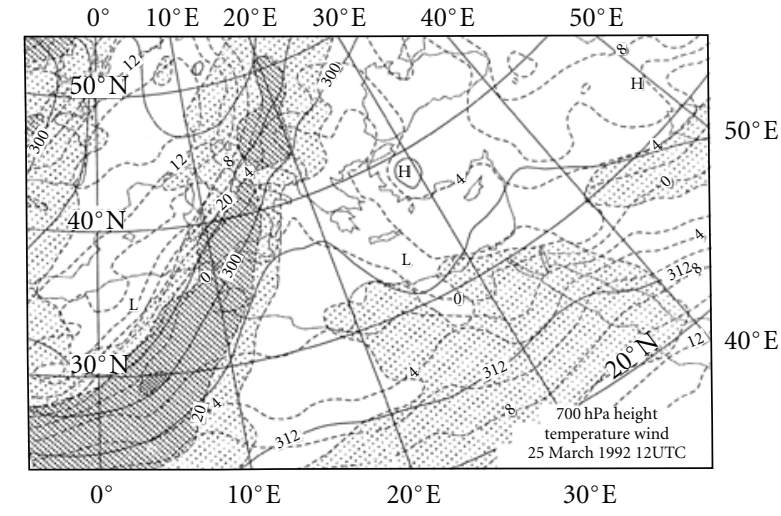

(b)

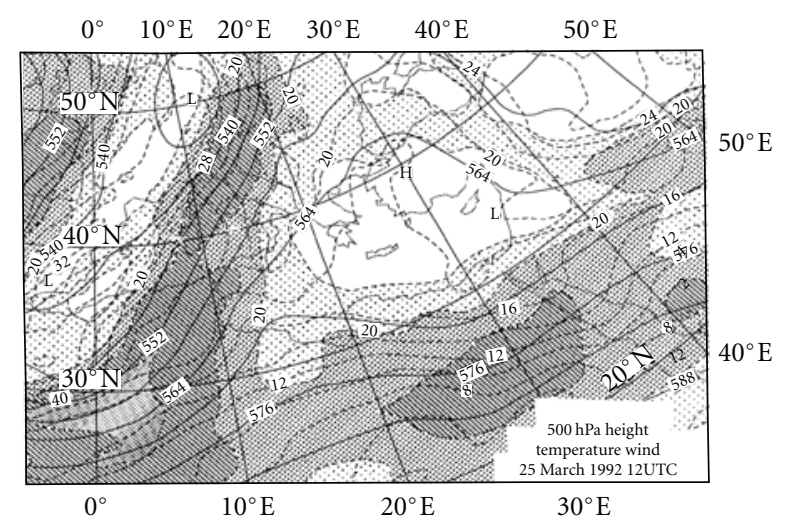

(c)

Figure 3: (a) Objective analysis of geopotential height and potential temperature at 850 hpa at 12:00 UTC on 25 March 1992. Geopotential contours: every $30 \mathrm{gpm}$, isentropes: every $2 \mathrm{~K}$, (b) $700 \mathrm{hpa}$ and (c) $500 \mathrm{hpa}$ at the same time and date. Contours are drawn every 60 gpm and isotherms every $2^{\circ} \mathrm{C}$. Wind speed above $30 \mathrm{~ms}^{-1}$ is stippled and more than this is shaded with shading increasing every $5 \mathrm{~ms}^{-1}$.

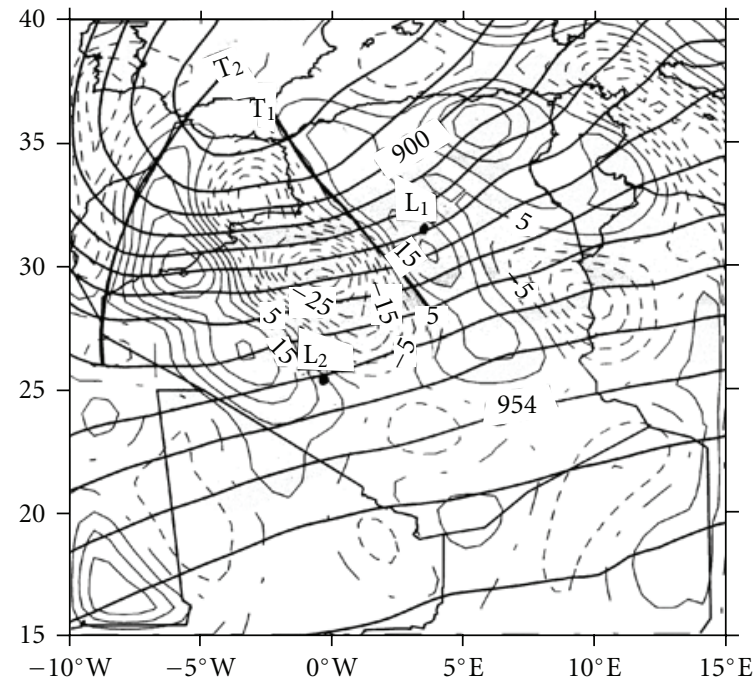

FIGURE 4: Objective analysis of geopotential height (thick continuous every $60 \mathrm{gpm}$ ) and absolute vorticity advection every $5 \times$ $10^{-10} \mathrm{~s}^{-2}$ at $300 \mathrm{hpa}$ at 12:00 UTC on 25 March 1992. Negative advection isopleths are dotted, and the zero one is dot-dashed. Positive advection isopleths are thin continuous. $\mathrm{L}_{1}$ and $\mathrm{L}_{2}$ denote the centres of the surface depressions, and $T_{1}$ and $T_{2}$ are the corresponding trough lines. appearing $12 \mathrm{~h}$ later (not shown). At this time the area of positive absolute vorticity advection is lying over an area of maximum thermal advection at the 850 hpa surface. This cyclogenesis belongs to type B cyclogenesis of Petterssen and Smebye [46], since there is significant warm advection in the region of surface cyclogenesis while the earlier development resulting in depression $\mathrm{L}_{1}$ belongs to type A cyclogenesis.

Following Hoskins et al. [47] we can describe almost the same process for the above cyclogenesis replacing the positive absolute vorticity advection with a potential vorticity anomaly at the upper levels and the shallow frontal surface with a low level baroclinic zone or with a low level potential vorticity anomaly [48]. These two approaches to the surface cyclogenesis process are advocated by Prezerakos [31], Prezerakos et al. [32], and Thorncroft and Flocas [27] in their findings about the baroclinic character of the Atlas depressions.

During the next $48 \mathrm{~h}$ the direction of the tropospheric flow at all the isobaric levels remains almost constant making the atmospheric circulation systems, surface depressions, and upper air troughs move north-eastwards (Figures 5 and 6). Thus, depression $\mathrm{L}_{1}$ (Figure 5), being associated with trough $\mathrm{T}_{1}$ in the south of Atlas Mountains at 12:00 UTC on 25 March 1992 (Figure 4), moves to a position with 


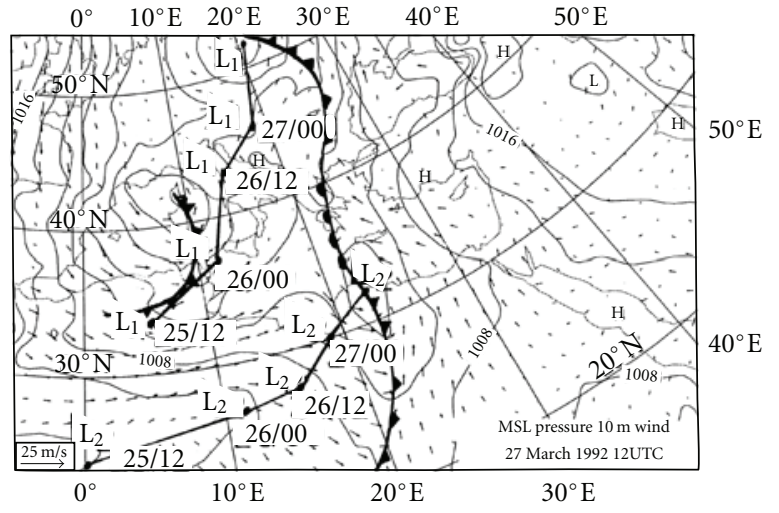

FIGURE 5: Same as Figure 1, but for 27 March 1992/12:00 UTC. Dots and straight segments show the successive 12-hour positions and tracks of the surface depressions $\mathrm{L}_{1}$ and $\mathrm{L}_{2}$. The numbers $\mathrm{dd} / \mathrm{hh}$ denote day and hour.

its centre located at $50^{\circ} \mathrm{N}, 21^{\circ} \mathrm{E}$ at $12: 00 \mathrm{UTC}$ on 27 March 1992 (Figure 5) ahead of trough $\mathrm{T}_{1}$ (Figure 6) which followed almost the same path. Trough $\mathrm{T}_{2}$, lying behind $\mathrm{T}_{1}$ at 12:00 UTC on 25 March 1992 (Figure 4) is within an asymmetrical wind field with much stronger winds on its western side plus cold advection and an SW-NE orientation of its axis. Thus it intensified within the next $24 \mathrm{~h}$. Trough $\mathrm{T}_{2}$, following a path almost parallel to that of trough $\mathrm{T}_{1}$ but more southerly, arrives at a position just southwest of Greece at 12:00 UTC on 27 March 1992 (Figure 6) making the advection of absolute vorticity toward Greece positive enough to create strong upward vertical motion over the Athens region at 700 and 500 hpa levels.

Figure 7 shows that the maximum values of the upward synoptic-scale velocities at 700 and 500 hpa levels are 2.8 and 3.0 $\mathrm{Pas}^{-1}$.

The combination of the warm air advection-caused by depression $\mathrm{L}_{1}$ at lower levels - and cold air advection at upper levels (the lowest temperatures in the vicinity of trough $\mathrm{T}_{2}$ are $-27^{\circ} \mathrm{C}$ at $500 \mathrm{hpa}$ level and $-48^{\circ} \mathrm{C}$ at $300 \mathrm{hpa}$ level) contributes significantly to this upward motion regime over Athens, leading to destabilization of the air mass. As the air mass ascends, the water vapour contained cools due to adiabatic expansion and clouds are formed using as condensation nuclei a part of the dust grains at higher levels, while the remaining dust grains and those drifting at lower levels are drawn away down by the rain.

3.2. Trajectories. The best way to diagnose and identify the sources of the air at various levels up to $500 \mathrm{hpa}$ above Athens and Thessaloniki regions at the time of the appearance of coloured rain is to calculate backward trajectories arriving at the point and time under consideration (here Athens and Thessaloniki at 12:00 UTC on 27 March 1992). Figure 8(a) shows such trajectories. It can be seen that the air at 850 and $700 \mathrm{hpa}$ at 12:00 UTC on 27 March 1992 above Athens was, $48 \mathrm{~h}$ previously (25 March/12:00 UTC), over Libya (Figure 8(a) left) behind a surface high at the south-eastern

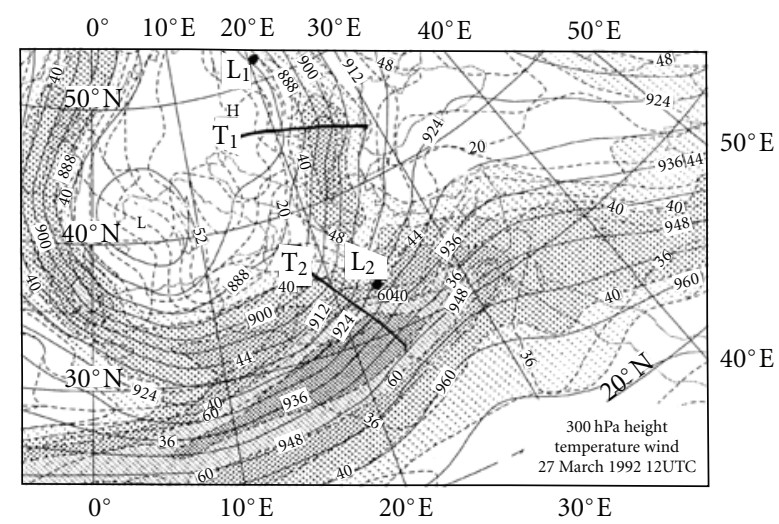

FIGURE 6: Objective analysis of geopotential height, temperature, and jet stream axes for $300 \mathrm{hpa}$ on 27 March 1992/12:00 UTC. Geopotential contours: every $60 \mathrm{gpm}$, isotherms: every $2^{\circ} \mathrm{C}$, and jet stream axes denote wind speed more or equal to $30 \mathrm{~ms}^{-1} ; \mathrm{T}_{1}$ and $\mathrm{T}_{2}$ are trough lines and $\mathrm{L}_{1}$ and $\mathrm{L}_{2}$ the surface depression centres.

most flank of depression $\mathrm{L}_{2}$ (Figure 1) at a height of about $1000 \mathrm{~m}$ (air reaching $850 \mathrm{hpa}$ above Athens was at $910 \mathrm{hpa}$ and air reaching $700 \mathrm{hpa}$ above Athens was at $890 \mathrm{hpa}$ as Figure 8(a) right shows).

The air at these levels came from the region where depression $\mathrm{L}_{1}$ initiated. Also, the air at $500 \mathrm{hpa}$ over Athens at 12:00 UTC on 27 March 1992 was, $48 \mathrm{~h}$ earlier (25 March/12:00 UTC), at a level of $800 \mathrm{hpa}$ to the south of the Atlas Mountains, where the depression $\mathrm{L}_{1}$ was developing. This air at $800 \mathrm{hpa}$ level is likely to contain dust grains and to carry them for a long distance over Greece. On the other hand, the air near the surface has come to Athens following a path passing through southwest Turkey and north Crete toward Athens with little likelihood of containing dust.

Figure 8(b) shows the same trajectories for Thessalonica, in northern Greece, where the coloured rain appeared in smaller amounts of $6 \mathrm{~mm} / 12 \mathrm{~h}$, almost all trajectories come from the region where depression $\mathrm{L}_{1}$ developed $48 \mathrm{~h}$ earlier. The trajectory which brings the air to the arrival point at $850 \mathrm{hpa}$ is the most important one, since $60 \mathrm{~h}$ before it is at the region, where depression $\mathrm{L}_{1}$ was developing (Figure 8(b) left and Figure 1), it was at a height of $930 \mathrm{hpa}$ (about $700 \mathrm{~m}$ ) (Figure 8(b) right) and likely to have acquired significant quantities of dust and to convey it for a very long distance. The lowest trajectory comes from the eastern Mediterranean Sea. It brings moisture due to its path being tracked over the sea but does not carry dust or sand particles.

From the above discussion it can be claimed that the calculation of trajectories by a global or regional sophisticated numerical model using initialized analyses every $6 \mathrm{~h}$ is the best way to detect the source and the course of the dust or the sand which is responsible for the creation of coloured rain falling over Greece and generally over the South Balkans.

3.3. Satellite Images. Satellite images are a useful tool to detect sand clouds. During the initial process of the dust cloud formation and the depression development over the north Sahara it is very difficult to identify the dust cloud 


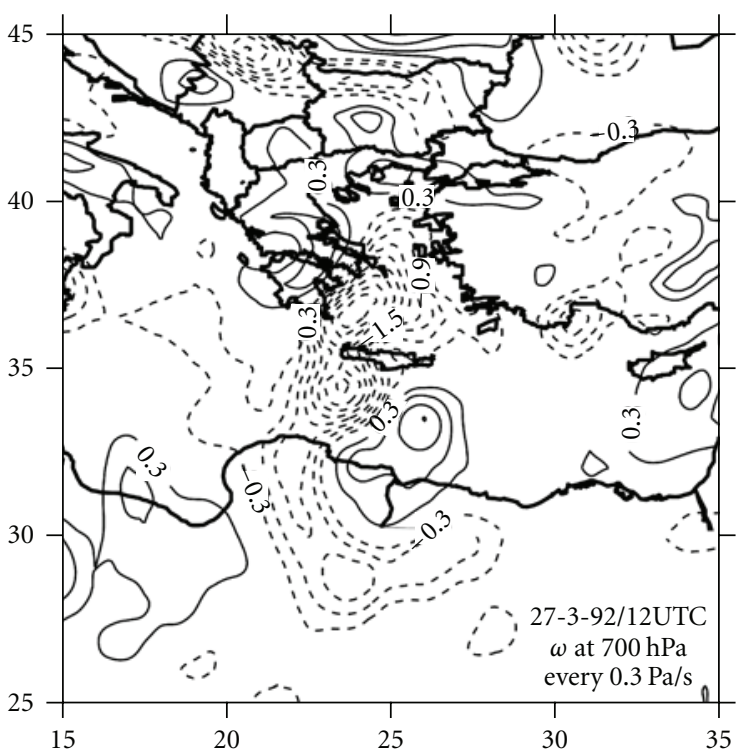

(a)

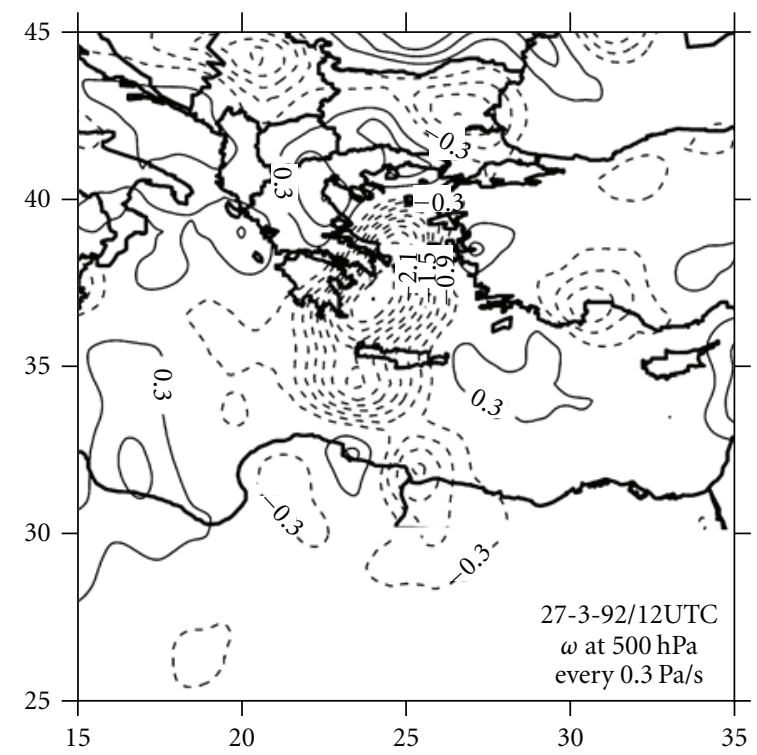

(b)

Figure 7: Same as Figure 2, but for (a) 700 hpa and (b) 500 hpa for 27 March 1992/12:00 UTC.

in the visible band since, being still near the ground, the dust cloud exhibits almost the same reflectivity as the ground below. Infrared imagery should overcome this difficulty because, during daytime, measurements by Ackerman and Inoue [49], Ackerman [50], and Wald [51] show that the thermal gradient is so strong near the overheated arid surfaces that 10-20 K [52] are typical values of the difference between the "skin" surface temperature and the air temperature at $2 \mathrm{~m}$. Therefore a dust layer is colder than the surface by at least this value and can be detected by the satellite radiometer NOAA 11 . Unfortunately infrared imagery at 12:00 UTC on 25 March 1992 over the source of the dust cloud in NW Sahara was not available. However, when the sand cloud moved on to a position over the Mediterranean Sea, then the necessary differences in reflectivity existed and there was a better temperature contrast between the dust cloud and the sea surface below, especially where the sea was rough. In this case, the dust cloud can be easily identified from the sea surface below, because it appears in the imagery as white or light grey and the sea surface as black in both visible and infrared images.

Combining the visible imagery of NOAA 11 received at 12:24 UTC on 26 March 1992 (Figure 9(a)) and Figure 8 showing the trajectories coming to Greece, we can detect (Figure 9(a), where the arrow points) a dust cloud at low levels between Libya and Greece moving towards Greece. Twelve hours later the sand cloud has reached Greece, while in twelve hours more two clouds of dust particles have entered the Mediterranean Sea coming from Tunisia and Libya (Figure 9(b), where the arrows point).

By making use of satellite pictures in association with forecasting trajectories, it is possible to forecast the time of coloured rain appearance in the South Balkans.

\section{Analysis and Discussion of the 4th April 1988 Case of Dust Deposit in North Greece}

During the morning on 4th April 1988 fine sand deposits occurred in north-eastern Greece and especially upon Thessalonica. As this phenomenon has already been investigated synoptically by Makrogiannis et al. [26], we will give only a brief description of the synoptic-scale atmospheric circulation associated with it and focus on the NOAA AVHRR images and the 2-day backward trajectories, which are parts of the computed 5-day backward ones, using the methodology described in Section 2. Although the chemical and aeromicrobiological nature of the dust deposit was investigated by many scientists in the last years [53-56], there is no data available for this case. Makrogiannis et al. [26] noted that "the National Commission of Environmental Protection announced that this was not a case of common Greek dust and hence did not cause any change in the concentration of sulphur dioxide, carbon dioxide and nitrogen oxides in air. The Laboratory of Nuclear Physics of the University of Thessalonica also announced that the dust in question was relatively more radioactive than the common Greek dust or sand found in the area."

Two days earlier at 00:00 UTC on 2 April 1988 an intensive depression developed covering almost all the northwest Sahara (Figure 10) accompanied by strong winds.

The main depression is moving north-eastwards so that, $24 \mathrm{~h}$ later, it is found over the coast of Tunisia in the Mediterranean Sea (not shown). The atmospheric conditions for a deep turbulent kinetic energy (TKE) field and a very deep mixing layer, which over the desert, reaches up to a depth of over $5 \mathrm{~km}$ during the hours of daylight, are thus favourable for fluxes of dust from the land to the atmosphere, which increase during the less stable daytime 

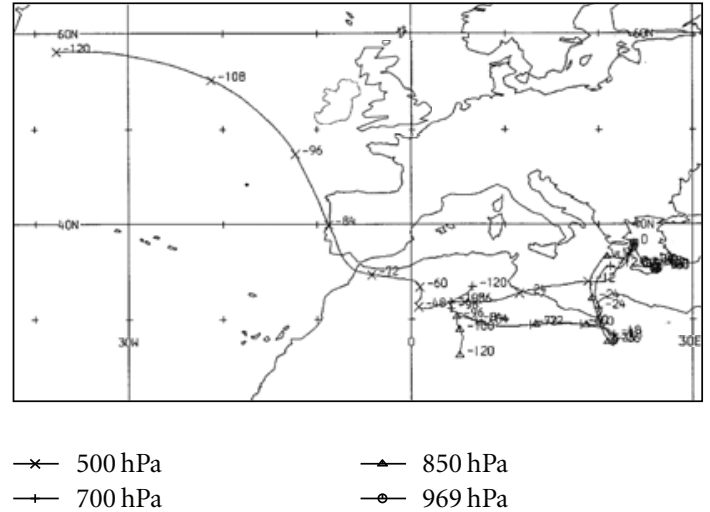

(a)

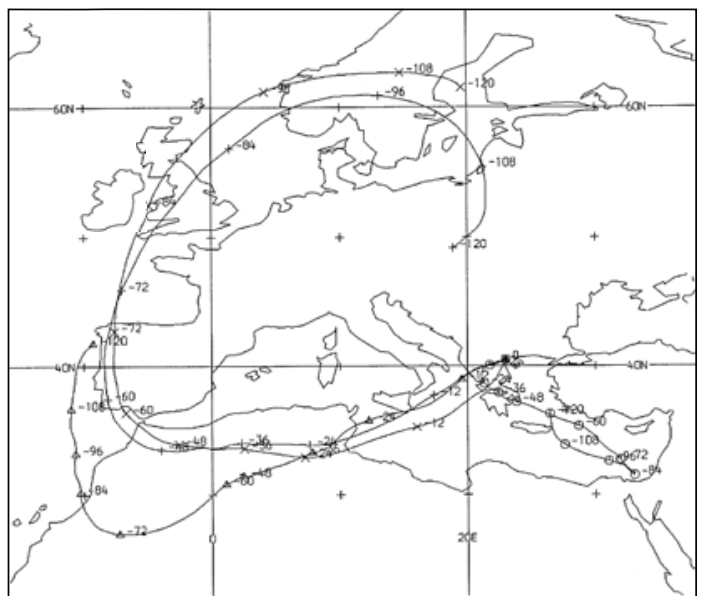

$\rightarrow 500 \mathrm{hPa} \quad \longrightarrow 850 \mathrm{hPa}$

$\rightarrow 700 \mathrm{hPa} \rightarrow 937 \mathrm{hPa}$

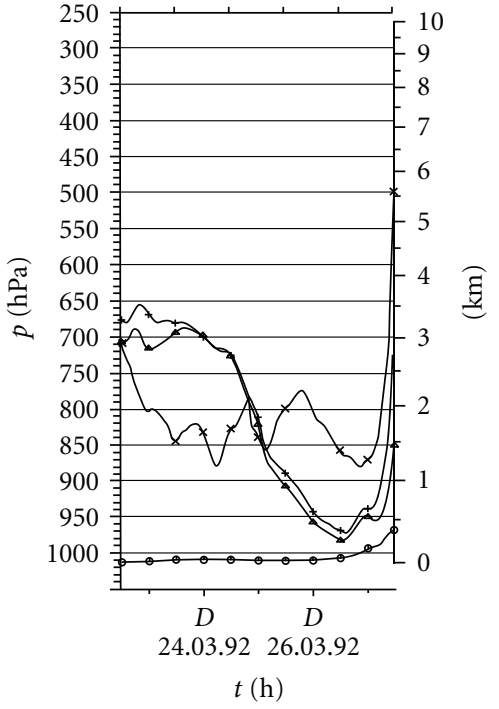

$* 500 \mathrm{hPa} \rightarrow 850 \mathrm{hPa}$
$+700 \mathrm{hPa} \rightarrow 969 \mathrm{hPa}$

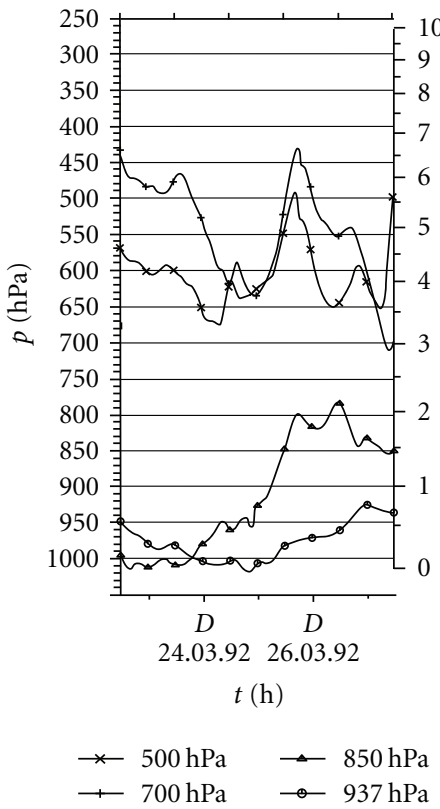

(b)

FIGURE 8: Backward trajectories with arrival (starting) point of (a) Athens $\left(23.72^{\circ} \mathrm{E}, 37.97^{\circ} \mathrm{N}\right)$ and (b) Thessalonica at $12: 00 \mathrm{UTC}$ on 27 March 1992. Left part shows geographical positions and time (hours from the arrival time), and the right part shows vertical positions and time.

boundary layer conditions and reach a peak in the early afternoon. As a result, large amounts of fine sand grains smaller than $20 \mu \mathrm{m}$ (dust) were stirred up in the form of a dust cloud with vertical velocities very much greater than the synoptic-scale ones. The synoptic-scale velocity values are about $-0.6 \mathrm{Pas}^{-1}$ at $850 \mathrm{hpa}$ and $-0.5 \mathrm{Pas}^{-1}$ at $700 \mathrm{hpa}$ level, especially at the vicinity of the depression's centre (not shown). As the atmospheric flow in the entire troposphere was south-westerly (Figures 11(a) and 11(b)), the dust cloud was conveyed north-eastwards.
This movement is fully supported by the two-day parts of the computed 5-day backwards trajectories depicted by Figure 12 and the NOAA AVHRR images (Figures 13(a) and $13(\mathrm{~b}))$. Three of the trajectories calculated to arrive over Thessalonica at 00:00 UTC on 4 April 1988 (namely at $300,500,700$, hpa heights) came from the southwest. The air parcels associated with the $300 \mathrm{hpa}$ and $500 \mathrm{hpa}$ trajectories are found over the region of the strong pressure gradients, thus where the sandstorms were $48 \mathrm{~h}$ previously. The calculated air parcels heights at 00:00 UTC/2 April 1988 


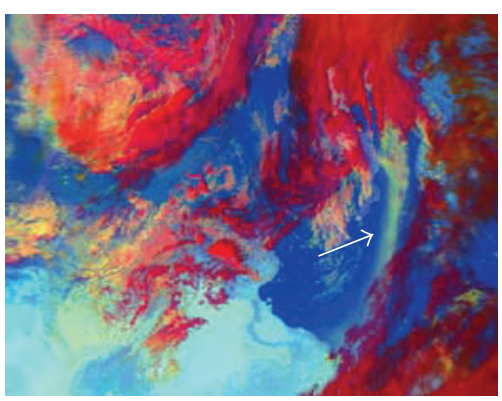

(a)

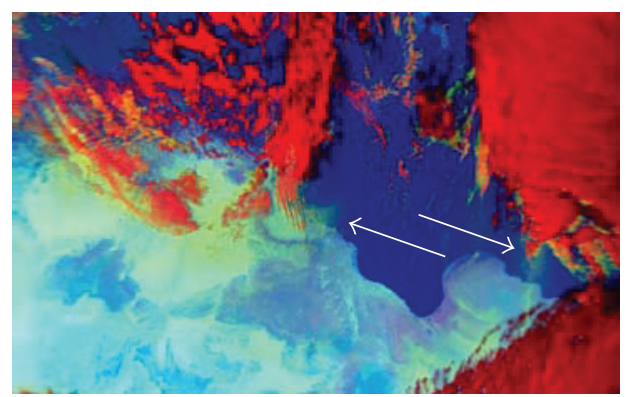

(b)

FIGURE 9: NOAA11 AVHRR satellite visible images received at (a) 12:24 UTC on 26 March and (b) 12:12 UTC on 27 March 1992.

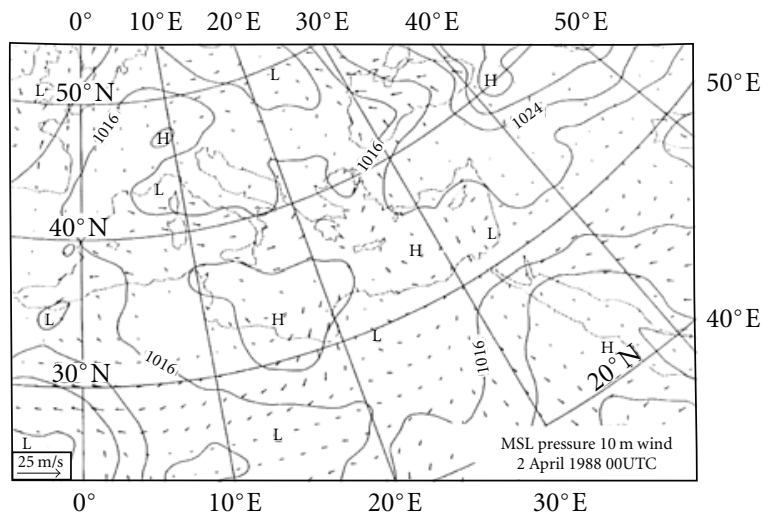

Figure 10: Same as Figure 1, but for 00:00 UTC on 2 April 1988.

are $835 \mathrm{hpa}$ for the $300 \mathrm{hpa}$ trajectory and $804 \mathrm{hpa}$ for the 500 hpa trajectory, that is, they were fully inside the mixing layer. The forming dust cloud will have extended up to the mixing layer top, that is, over $5 \mathrm{~km}$, and it will travel together with the air parcels between $500 \mathrm{hpa}$ and $300 \mathrm{hpa}$ trajectories rising continuously in the beginning of the period. But later the dust cloud moves far from the source region and the deep mixing layer. Thus it diffuses, becoming sparse and independent whether being in a synoptic-scale downward or ordinary upward vertical motion field, and it slightly subsides due to the force of gravitation.

At the same time the air parcels associated with the 700 hpa trajectory can be found 48 hours before their arrival over Thessalonica at the south borders of Tunisia and Libya $\left(16^{\circ} \mathrm{E}, 26^{\circ} \mathrm{N}\right)$ at a height of $757 \mathrm{hpa}$ (Figure 13) where a secondary depression is developing in the neighbourhood of a surface anticyclone. Strong pressure gradients are produced in this region causing dust storms. This trajectory, waving up and down slightly, is directed towards south Italy being at 830 hpa level over the Mediterranean Sea. Almost all trajectories converge at the atmospheric layer between about 850 and 700 hpa levels over southeast Italy as they approach North Greece.

Examining a coloured NOAA satellite image on 2 April 1988 at 14:17 UTC produced by AVHRR channels 4, 5, and 4 inverted after processing, we are able to observe the dust cloud. On this image yellowish pixels represent large areas of the dust clouds coming from northern Africa and are mostly to be found over the Mediterranean close to the Tunisia coastline. A secondary dust maximum shown in the Adriatic sea seems not to be associated with the dust settled at Thessalonica $36 \mathrm{~h}$ later because it is much northern than Thessalonica, and the lower tropospheric circulation, west of northern Greece, is intensively southern. Also on this image clouds are blue or dark blue and land gets an orange or reddish colour. The main dust cloud is shown clearly in the coloured version of the abovementioned image where the letter $\mathrm{S}$ is (Figure 13(a)).

On the next day (14:17 UTC on 3 April 1988) all the area of Italy, Greece, and Algeria is covered by clouds as shown in another coloured image (Figure 13(b)) and it is difficult to recognize the dust, which is embedded in them. However, where the clouds are broken, we are able to see the yellow pixels of the dust close to south Italy extending towards the coasts of Algeria and Tunisia where a dust cloud is depicted clearly. On this coloured image, a different image processing approach has been applied than that on the previous one. On this image clouds are white, sea is blue, and land is green. Dust remains yellow. These pieces of evidence lead us to the estimation that the region between letters $\mathrm{C}$ and $S$ (Figure 13(b)) is covered by the dust cloud (the colour AVHRR images were received from University of Dundee). It is evident that the dust plume observed more west, where the letter $\mathrm{C}$ is, would rather be associated to a Sahelian source as 500 and 300 hpa back trajectories indicate (Figures 13(b) and 12).

During the 12-hour interval, (that is, between 00:00 and 1200 UTC on 3 April 1988) the atmospheric circulation remains anticyclonic over West and North Greece (Figures 14(a) and 14(b)) with a distinct synoptic scale surface anticyclone at 12:00 UTC on 3 April 1988 (Figure 15).

In the next hours the surface anticyclone advances north-eastwards while an intensive field of upward synoptic scale motion dominates over Greece, especially west of Thessalonica. At the same time over the sea south of Italy a field of downward vertical synoptic scale of atmospheric motion is established (Figure 16). At that region the 700, 500 , and 300 hpa trajectories converge facilitating the transport of dust to Thessalonica ground following often the isentropes, keeping the falling even at 00:00 UTC on 4 April 1988, although upward synoptic-scale vertical motion 


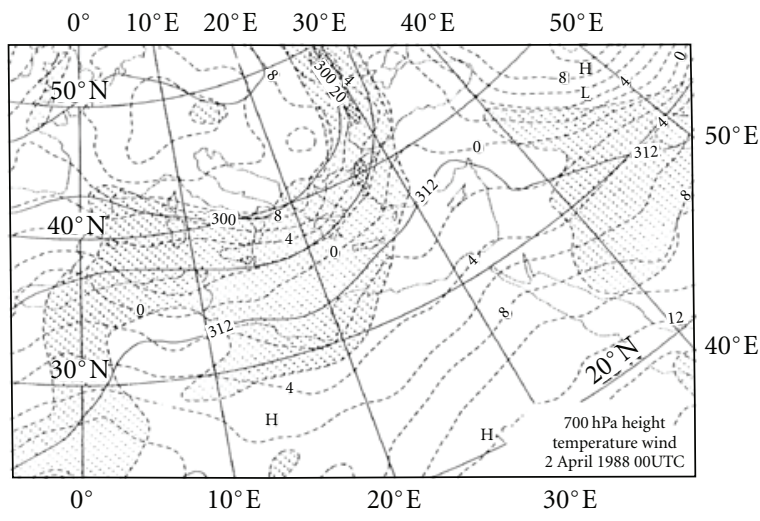

(a)

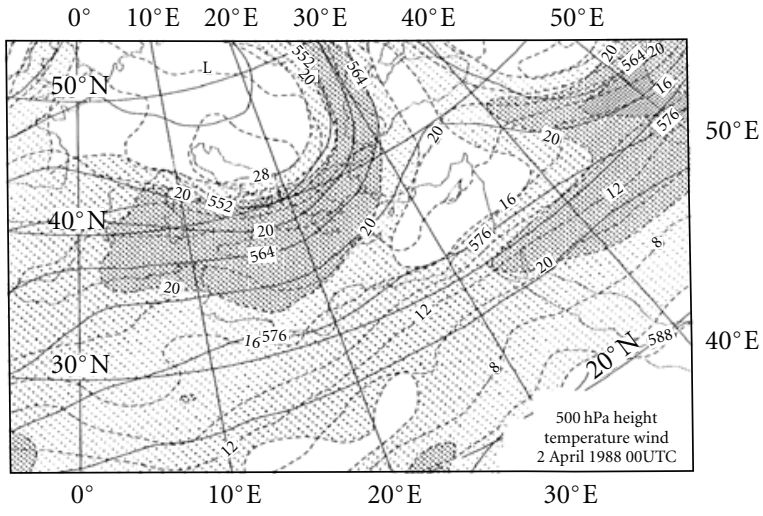

(b)

Figure 11: Same as Figures 3(b) and 3(c), but for 00:00 UTC on 2 April 1988, (a) 700 hpa and (b) 500 hpa.
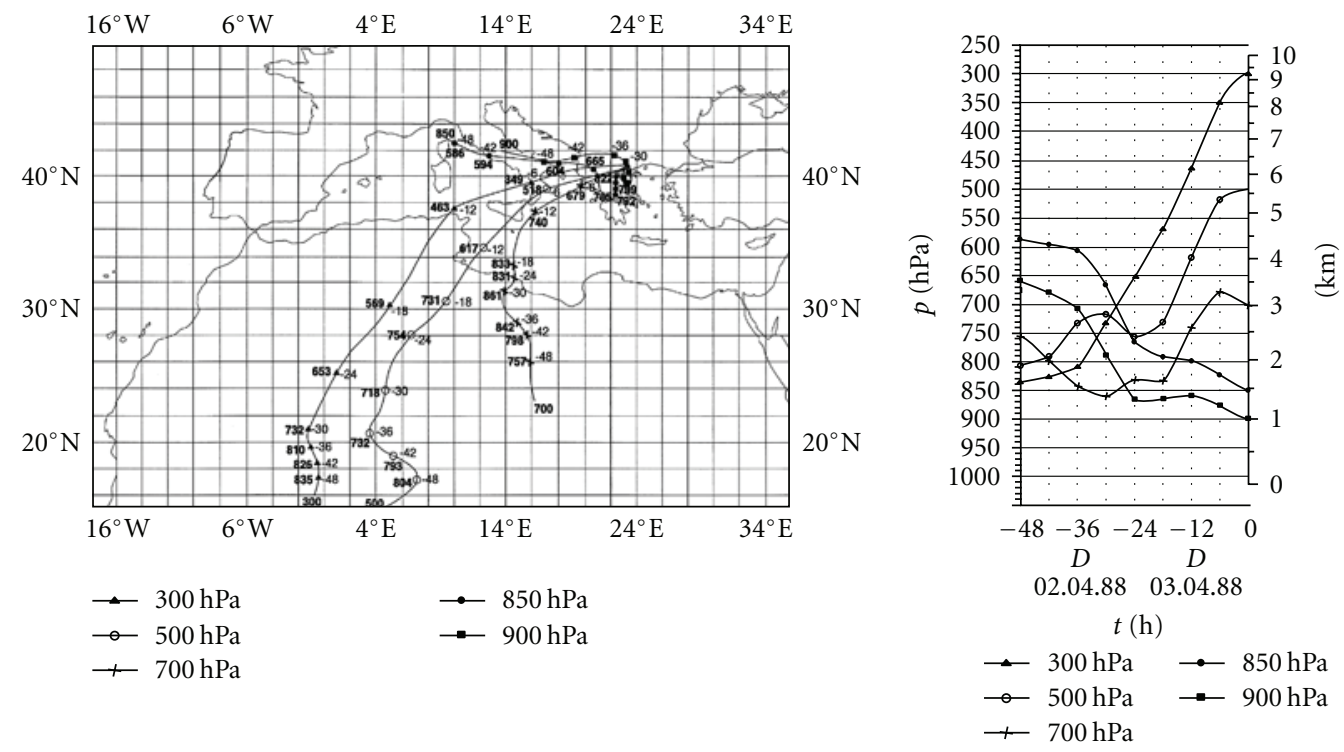

Figure 12: Same as Figure 8(b), but for 00:00 UTC on 4 April 1988.

was maintaining over Thessalonica (Figure 16(b)). The final result was deposits of fine sand being left visible on the roofs of the cars. This last one is an irrefutable fact coming from the observation.

The above analysis showed that the dust has come from the region where the dust storms appeared two days earlier. The trajectories arriving at Thessalonica came from the area of interest starting from inside a very deep mixing layer. This fact and the irrefutable fact of dry dust deposit upon Thessalonica ground lead us to the conclusion that (i) a dust cloud after being stirred up to the top of mixing layer in this case at a height of five $\mathrm{km}$ as mentioned above can travel over a large distance if it is in an atmospheric environment of strong upward vertical motion resisting the gravity, and (ii) when a dust cloud, which has already been diffused and moved out of its source area, is found in an environment of downward vertical motion or in ordinary synoptic-scale upward motion, the dust will start to fall out under the force of gravity after reaching a critical downward velocity. Figure 12 right shows that this occurred for the 700, 500 , and $300 \mathrm{hpa}$ trajectories $30 \mathrm{~h}$ to $24 \mathrm{~h}$ before arriving at Thessalonica. They then moved into a subsiding region and converged over South Italy and north Ionian Sea in the layer $800-700 \mathrm{hpa}$. The dust cloud in this layer is forced at this time by the subsiding motion of the trajectories, and the particles, accelerated by gravity, continually fall out into lower levels forwarding at the same time following the wind direction. Thus, eventually, the south-westerly air flow with its load of sand grains lands at North Greece and reaches Thessalonica. This dust layer $800-700 \mathrm{hpa}$ having a gravitational settling velocity of $\sim 10 \mathrm{cms}^{-1}$ should take about $10 \mathrm{~h}$ to reach the ground, but the dust cloud moving 


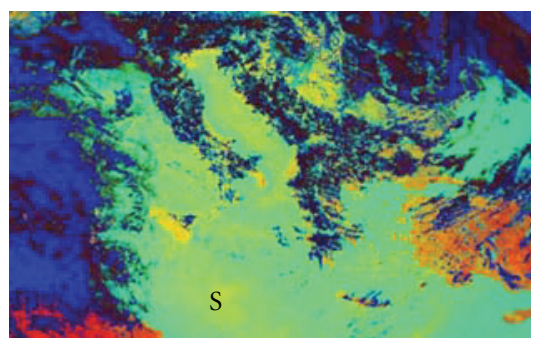

(a)

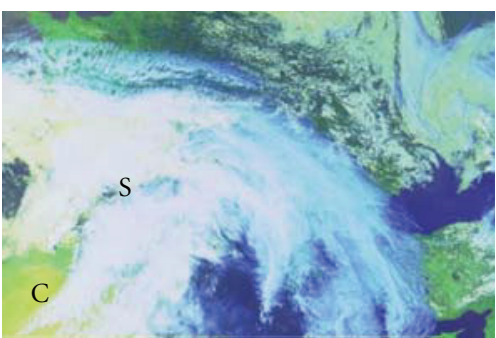

(b)

Figure 13: NOAA AVHRR images coloured versions (a) of channels 4, 5, and 4 inverted at 14:17 UTC on 2 April 1988 and (b) of channel 4 at 14:17 UTC on 3 April 1988.

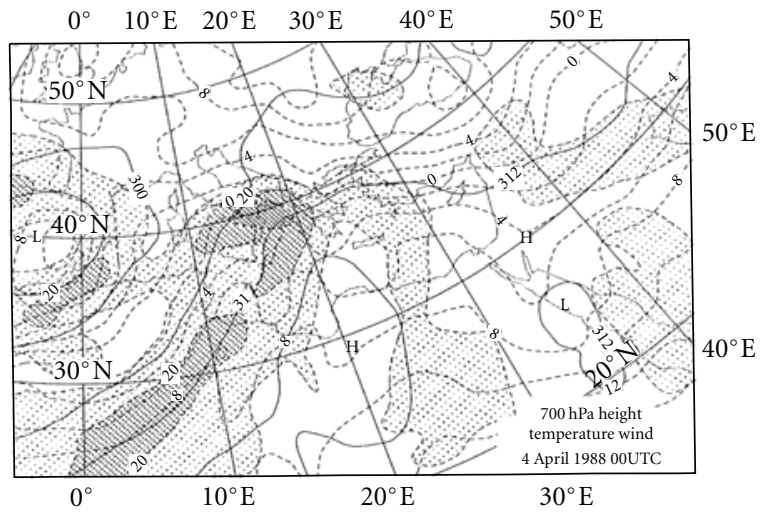

(a)

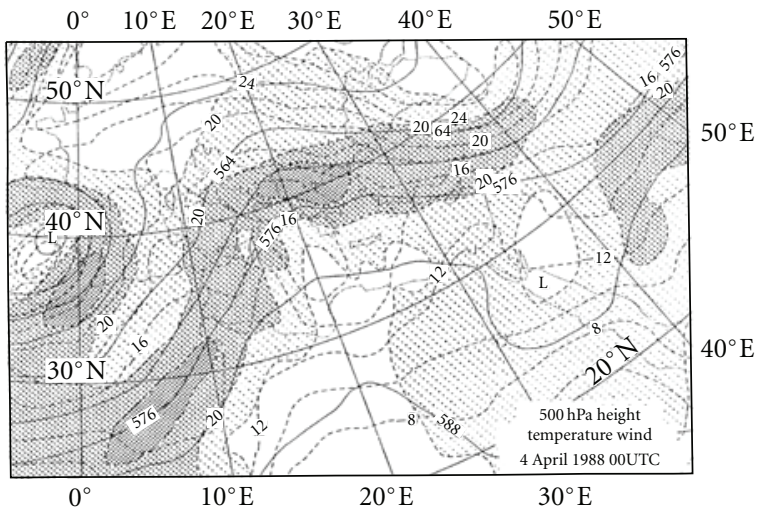

(b)

FIgURE 14: Same as Figures 3(b) and 3(c), but for 00:00 UTC on 4 April 1988, (a) 700 hpa and (b) 500 hpa.

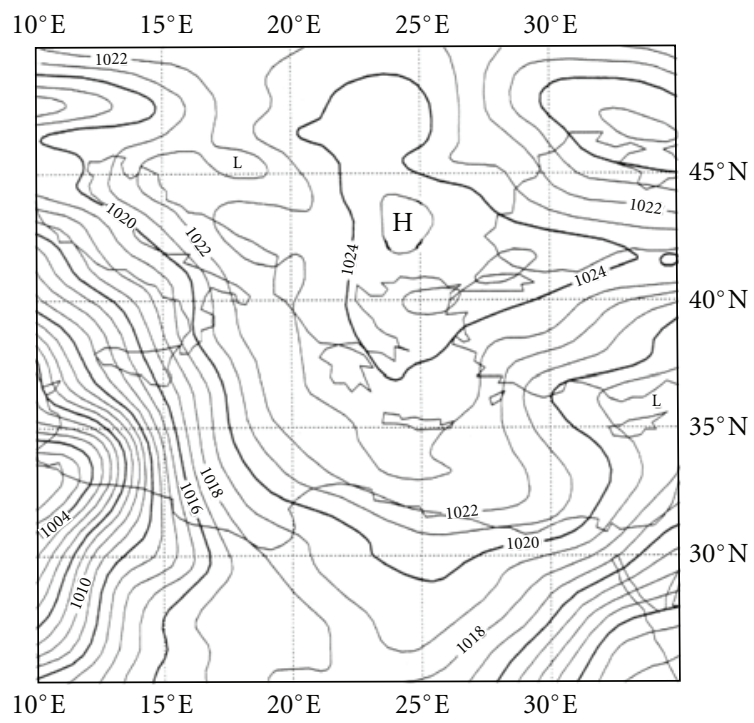

Figure 15: Same as Figure 1, but for 12:00 UTC on 3 April 1988. Isobars: every $1 \mathrm{hpa}$.

eastwards to Thessalonica enters a field of strong upward synoptic scale atmospheric motion contrasting the gravity fall reducing very much the gravitational settling velocity, thus justifying the length of time of approximately $24 \mathrm{~h}$ for the particulate to finally settle down in Thessalonica. To better clarify the dry deposition mechanism, the presentation of time series of PM concentrations in Thessalonica would be very useful, but such data is not available. During that period only gas pollutants were being observed.

\section{Concluding Remarks}

In this study we have attempted to examine the phenomenon of significant dust deposits over Greece through the analysis of two case studies. The first case study is relevant to the coloured rain which occurs frequently over Greece and the second case study to the very rare cases of dust deposit. This second phenomenon, consisting of a large amount of dust deposit which is visible on the streets, the car, and house roofs, has occurred only once in the last twenty years, on 4 April 1988 over northern Greece. On the other hand throughout the year, and especially during spring, there are often very light, barely visible dust deposits over the South Balkans. Both phenomena are associated with the appearance of depressions that are generated in northwest Sahara, to the south of the Atlas Mountains especially during spring $[3,18,33,34]$.

It was found that, two days before the occurrence of the dust deposit over Greece, a sand storm appeared over the northwest part of the Sahara desert due to a vigorous Atlas mountain depression. The flow in the entire troposphere, and especially in its lower half where the dust grains in the 


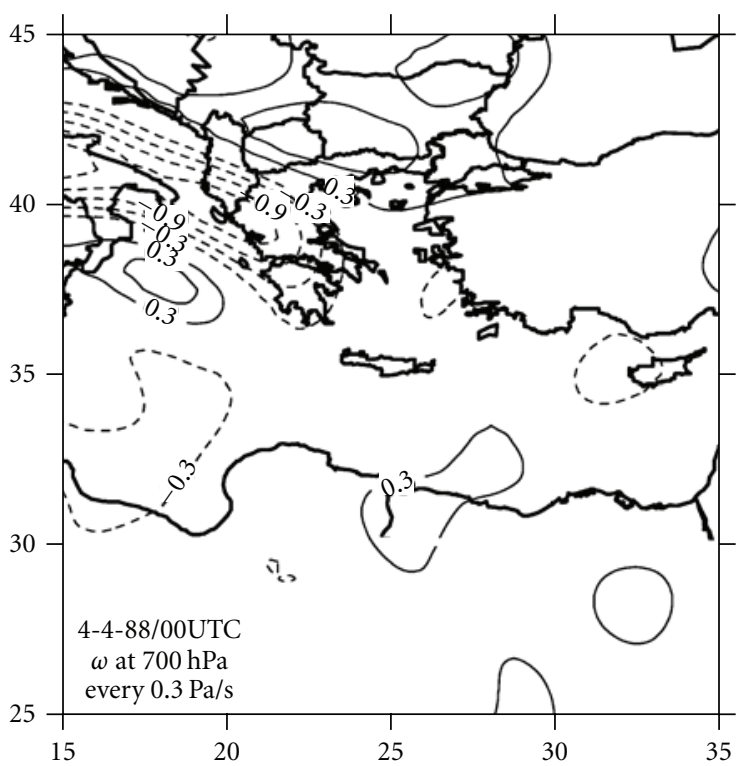

(a)

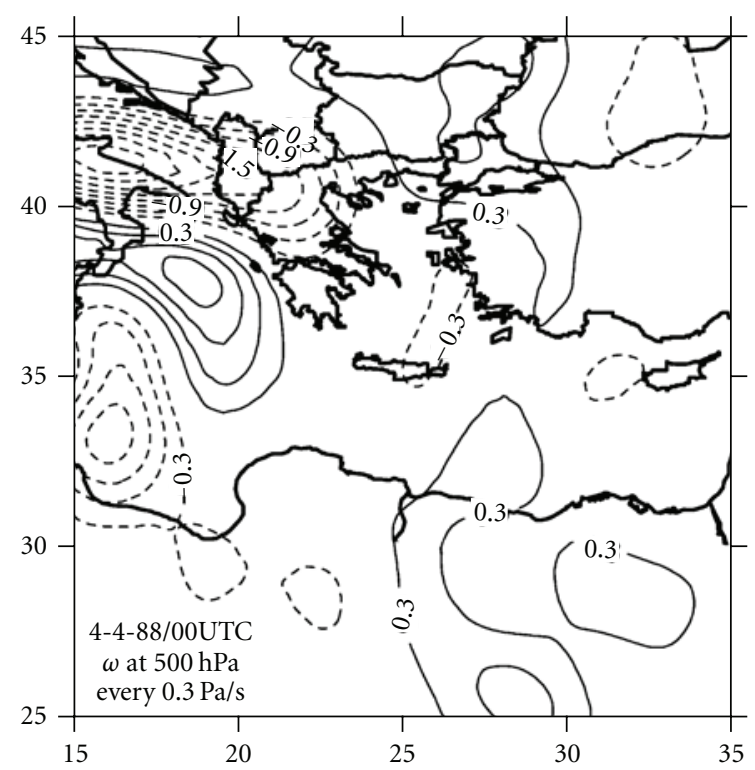

(b)

Figure 16: As Figure 2, but for 00:00 UTC on 4 April 1988, (a) 700 hpa and (b) 500 hpa.

form of a dust cloud could be stirred up, was S-SW carrying the dust cloud for a long distance reaching Greece and the South Balkans.

In the case of coloured rain, the dust cloud arrived over Greece with warm air advection and upward synopticscale vertical motion resulting in the cooling of the water vapour contained due to adiabatic expansion and clouds were formed using as condensation nuclei a part of the dust grains at higher levels while the remaining dust grains and those drifting at lower levels were drawn away down by the rain.

In the case of the dry dust deposit upon Thessalonica the atmospheric circulation at the start of the route of the dust cloud was intensively cyclonic while over the route about $30 \mathrm{~h}$ to $24 \mathrm{~h}$ before the dust appearance it was intensively anticyclonic resulting in the initiation of large-scale subsidence. This together with the contributing downward gravitational motion resulted in the occurrence of widespread dust deposit on the surface although upward large-scale synoptic motion regime dominated over Thessalonica.

Air backward trajectories starting from the time and the point under consideration confirm the origin of the dust cloud but the justification given of the dry dust deposit over Thessalonica ground is rather complicated and not absolutely clear. Also, AVHRR satellite images were able to give information on the base height and the depth of the dust cloud, when this was positioned away from the Sahara, over the Mediterranean Sea.

It should be noted that the process followed, leading to the development of the Atlas depression necessary for the occurrence of a dust storm, is the usual one characterizing the baroclinic waves and starting when the PFJ migrates southwards enough to reach the Atlas Mountains of northwest Africa. Good example cases could be found on the
EUMETSAT web page: http://www.eumetsat.int/ (satellite images of the month).

Finally it would be mentioned that special attempt has been done for the physical justification of the fact that deposits of fine sand are left visible especially on the roofs of the cars in Thessalonica in the morning on 4th April 1988. The inclusion of time series of PM concentration would strengthen the analysis, but unfortunately such data is not available. For those readers who are not satisfied with the justification given, the road is open for complementary research using more advanced scientific tools. We may continue our attempt for a future second paper including in our scientific tools the Athens University Eta model (Professor G. Kallos research group). This sophisticated model $[17,22]$ that has been under continuous upgrading proved very effective in predicting the dust cycle (suspension, transport, concentration, and deposition) in every day weather forecasts.

\section{Acknowledgments}

The authors wish to thank Dr. David Axford, former deputy Secretary General of World Meteorological Organization (WMO) for his constructive comments, ECMWF, DWD, associate Professor H. Feidas, and Dr. A. Anthis, for the provided data. Also, the authors would like to thank the reviewers for their very constructive and detailed comments.

\section{References}

[1] V. E. Angouridakis, A Case of Coloured Rain in the Area of Thessaloniki, Meteorologika, no. 14, University of Thessaloniki, 1971. 
[2] S. Karoulias, The Saharian Depressions, Meteorologika, no. 57, University of Thessaloniki, 1971.

[3] N. G. Prezerakos, "The northwest African depressions affecting the south Balkans," Journal of Climatology, vol. 5, no. 6, pp. 643-654, 1985.

[4] M. Athanassiadou, H. Flocas, M. A. J. Harrison, M. C. Hort, C. S. Witham, and S. Millington, "The dust event of 17 April 2005 over Athens, Greece," Weather, vol. 61, no. 5, pp. 125$131,2006$.

[5] M. T. Tullet, "A dust fall on 6 March 1977," Weather, vol. 33, pp. 48-52, 1978.

[6] R. F. File, "Dust deposit in England on 9 November 1984," Weather, vol. 41, pp. 191-195, 1986.

[7] S. Rodríguez, X. Querol, A. Alastuey, G. Kallos, and O. Kakaliagou, "Saharan dust contributions to PM10 and TSP levels in Southern and Eastern Spain," Atmospheric Environment, vol. 35, no. 14, pp. 2433-2447, 2001.

[8] J.-B. Stuut, I. Smalley, and K. O’Hara-Dhand, "Aeolian dust in Europe: African sources and European deposits," Quaternary International, vol. 198, no. 1-2, pp. 234-245, 2009.

[9] J. M. Prospero, E. Bonatti, C. Schubert, and T. N. Carlson, "Dust in the Caribbean atmosphere traced to an African dust storm," Earth and Planetary Science Letters, vol. 9, no. 3, pp. 287-293, 1970.

[10] J. M. Prospero and T. N. Carlson, "Vertical and areal distribution of Saharan dust over the western equatorial North Atlantic Ocean," Journal of Geophysical Research, vol. 77, pp. 5255-5265, 1972.

[11] G. E. Shaw, "Transport of Asian desert aerosol to the Hawaiian Islands," Journal of Applied Meteorology, vol. 19, no. 11, pp. 1254-1259, 1980.

[12] Y. Iwasaka, H. Minoura, and K. Nagaya, "The transport and spacial scale of Asian dust-storm clouds: a case study of the dust-storm event of April 1979," Tellus, vol. 35B, no. 3, pp. 189-196, 1983.

[13] M. Uematsu, R. A. Duce, J. M. Prospero, L. Chen, J. T. Merrill, and R. L. McDonald, "Transport of mineral aerosol from Asia over the North Pacific ocean," Journal of Geophysical Research, vol. 88, no. C9, pp. 5342-5352, 1983.

[14] E. F. Danielsen, "The relationship between severe weather, major dust storms and rapid large-scale cyclogenesis, Parts I and II," in Subsynoptic Extratropical Weather Systems: Observations, Analysis, Modeling, and Prediction; Notes from a Colloquium: Summer 1974, vol. 2, National Center for Atmospheric Research, Boulder, Colo, USA, 1975.

[15] D. G. Kaskaoutis, H. D. Kambezidis, P. T. Nastos, and P. G. Kosmopoulos, "Study on an intense dust storm over Greece," Atmospheric Environment, vol. 42, no. 29, pp. 6884-6896, 2008.

[16] R. Jones, "Atmospheric dispersion modelling at the Met. Office," Weather, vol. 59, no. 11, pp. 311-316, 2004.

[17] G. Kallos, A. Papadopoulos, P. Katsafados, and S. Nickovic, "Transatlantic Saharan dust transport: model simulation and results," Journal of Geophysical Research, vol. 111, no. 9, Article ID D09204, 2006.

[18] N. Kubilay, S. Nickovic, C. Moulin, and F. Dulac, "An illustration of the transport and deposition of mineral dust onto the eastern Mediterranean," Atmospheric Environment, vol. 34, no. 8, pp. 1293-1303, 2000.

[19] B. Marticorena, G. Bergametti, B. Aumont, Y. Callot, C. N'Doumé, and M. Legrand, "Modeling the atmospheric dust cycle 2. Simulation of Saharan dust sources," Journal of Geophysical Research, vol. 102, no. 4, pp. 4387-4404, 1997.
[20] S. Michaelides, P. Evripidou, and G. Kallos, "Monitoring and predicting Saharan Désert dust events in the eastern Mediterranean," Weather, vol. 54, pp. 311-316, 1999.

[21] S. Ničković and S. Dobričić, "A model for long-range transport of desert dust," Monthly Weather Review, vol. 124, no. 11, pp. 2537-2544, 1996.

[22] S. Nickovic, O. Kakaliagou, G. Kallos, D. Jovic, and A. Papadopoulos, "Eta/dust model: sensitivity to model resolution and desert source specification," in Proceedings of the 1st LAS/WMO International Symposium on Sand and Dust Storms, WMO Programme on Weather Prediction Research Report Series Project no. 10, WMO Technical Document no. 864, pp. 187-196, Damascus, Syria, November 1997.

[23] S. Nickovic, G. Kallos, A. Papadopoulos, and O. Kakaliagou, "A model for prediction of desert dust cycle in the atmosphere," Journal of Geophysical Research, vol. 106, no. 16, pp. 1811318129, 2001.

[24] L. Carapiperis and A. Tataris, "Coloured rain during the 15 and 22 March of 1962," in Proceedings of the Academy of Athens, vol. 38, pp. 300-308, 1963.

[25] T. A. Charadonis, T. J. Makrogiannis, and A. A. Flocas, "The possibility of identification of sand clouds and prediction of coloured rain over Greece by mean of satellite imagery," Bulletin of the Geological Society of Greece, vol. 25, no. 4, pp. 303-314, 1991.

[26] T Makrogiannis, A. Flocas, N. Ramos, and A. Karipidis, "A case of dust fall and coloured rain in the Greek area," Rivista di Meteorologia Aeronautica, vol. 50, no. 1-2, pp. 65-74, 1990.

[27] C. D. Thorncroft and H. A. Flocas, "A case study of Saharan cyclogenesis," Monthly Weather Review, vol. 125, no. 6, pp. 1147-1165, 1997.

[28] Karein D., The forecasting of cyclogenesis in the Mediterranean region, Ph.D. thesis, University of Edinburgh, Edinburgh, Scotland, 1975.

[29] F. Defant, "On the hydrodynamic instability caused by approach of subtropical and polar front jet stream in northern latitudes before the onset of strong cyclogenesis," in Rossby Memorial Volume: The Atmosphere and Sea in Motion, B. Bolin, Ed., pp. 305-325, Rockefeller Institute, New York, NY, USA, 1959.

[30] N. G. Prezerakos, H. A. Flocas, and D. Brikas, "The role of the interaction between polar and subtropical jet in a case of depression rejuvenation over the Eastern Mediterranean," Meteorology and Atmospheric Physics, vol. 92, no. 1-2, pp. 139$151,2006$.

[31] N. G. Prezerakos, "Synoptic flow patterns leading to the generation of north-west African depressions," International Journal of Climatology, vol. 10, no. 1, pp. 33-48, 1990.

[32] N. G. Prezerakos, S. C. Michaelides, and A. S. Vlassi, "Atmospheric synoptic conditions associated with the initiation of north-west African depressions," International Journal of Climatology, vol. 10, no. 7, pp. 711-729, 1990.

[33] U. Dayan, J. Heffter, J. Miller, and G. Gutman, "Dust intrusion events into the Mediterranean basin," Journal of Applied Meteorology, vol. 30, no. 8, pp. 1185-1199, 1991.

[34] C. Moulin, C. E. Lambert, U. Dayan et al., "Satellite climatology of African dust transport in the Mediterranean atmosphere," Journal of Geophysical Research, vol. 103, no. D11, pp. 13137-13144, 1998.

[35] B. Marticorena and G. Bergammetti, "Modelling the atmosphere dust cycle: 1-Design of a soil-derived dust production scheme," Journal of Geophysical Research Atmospheres, vol. 100, 
pp. 16415-16430, 1995.

[36] D. Soderman and F. Dulac, "Monitoring and prediction of the atmospheric transport and deposition of desert dust in the Mediterranean region," in Programme on Weather Prediction Research (PWPR), vol. 10 of Report Series Project, pp. 181-186, World Meteorological Organization, Geneva, Switzerland, 1998.

[37] I. Tegen and I. Fung, "Modeling of mineral dust in the atmosphere: sources, transport, and optical thickness," Journal of Geophysical Research, vol. 99, no. D11, pp. 22897-22914, 1994.

[38] S. A. Grigoryan and M. A. Sofiev, "Numerical modeling of dust elevation during storm episodes and its long-range atmospheric transport," in Proceedings of the 1st LAS/WMO International Symposium on Sand and Dust Storms, WMO Programme on Weather Prediction Research Report Series Project no. 10, WMO Technical Document no. 864, pp. 8898, Damascus, Syria, November 1997.

[39] N G. Prezerakos, "Dust storms over Sahara Desert leading to dust deposit or coloured rain in the South Balkans," in Proceedings of the 1st LAS/WMO International Symposium on Sand and Dust Storms, WMO Programme on Weather Prediction Research Report Series Project no. 10, WMO Technical Document no. 864, pp. 21-38, Damascus, Syria, November 1997.

[40] C. Kottmeier and B. Fay, "Trajectories in the Antarctic lower troposphere," Journal of Geophysical Research, vol. 103, no. D9, pp. 10947-10959, 1998.

[41] World Meteorological Organization, World Weather Watch (WWW) Program, "Technical Progress Report on the Global Data-Processing System (GDPS)," Report Series 2, WMO, Geneva, Switzerland, 1995.

[42] N. Brooks and M. Legrand, "Dust variability over northern Africa and rainfall in the Sahel," in Linking Climate Change to Land Surface, S. J. McLaren and D. R. Kniveton, Eds., Springer, New York, NY, USA, 2000.

[43] P. Ginoux, M. Chin, I. Tegen, et al., "Global simulation of dust in the troposphere: model description and assessment," Journal of Geophysical Research Atmospheres, vol. 106, no. D17, pp. 20255-20273, 2001.

[44] J. M. Prospero, P. Ginoux, O. Torres, S. E. Nicholson, and T. E. Gill, "Environmental characterization of global sources of atmospheric soil dust identified with the Nimbus 7 Total Ozone Mapping Spectrometer (TOMS) absorbing aerosol product," Reviews of Geophysics, vol. 40, no. 1, p. 1002, 2002.

[45] S. Petterssen, Weather Analysis and Forecasting, vol. 1, McGraw-Hill, New York, NY, USA, 2nd edition, 1956.

[46] S. Petterssen and S. J. Smebye, "On the development of extratropical cyclones," The Quarterly Journal of the Royal Meteorological Society, vol. 97, no. 414, pp. 457-482, 1956.

[47] B. J. Hoskins, M. E. McIntyre, and A. W. Robertson, "On the use and significance of isentropic potential vorticity maps," The Quarterly Journal of the Royal Meteorological Society, vol. 111, no. 470, pp. 877-946, 1985.

[48] N. G. Prezerakos, H. A. Flocas, and S. C. Michaelides, "Absolute vorticity advection and potential vorticity of the free troposphere as synthetic tools for the diagnosis and forecasting of cyclogenesis," Atmosphere-Ocean, vol. 35, no. 1, pp. 65-91, 1997.

[49] S. A. Ackerman and T. Inoue, "Radiation energy budget studies using collocated AVHRR and ERBE observations,"
Journal of Applied Meteorology, vol. 33, no. 3, pp. 370-378, 1994.

[50] S. A. Ackerman, "Remote sensing aerosols using satellite infrared observations," Journal of Geophysical Research, vol. 102, no. D14, pp. 17069-17079, 1997.

[51] L. Wald, "Some terms of reference in data fusion," IEEE Transactions on Geoscience and Remote Sensing, vol. 37, no. 3, pp. 1190-1193, 1999.

[52] J. P. Frangi, A. Druilhet, P. Durand, H. Ide, J. P. Pages, and A. Tinga, "Energy budget of the Sahelian surface layer," Annales Geophysicae, vol. 10, no. 1-2, pp. 25-33, 1992.

[53] E. Katragkou, S. Kazadzis, V. Amiridis, V. Papaioannou, S. Karathanasis, and D. Melas, "PM10 regional transport pathways in Thessaloniki, Greece," Atmospheric Environment, vol. 43, no. 5, pp. 1079-1085, 2009.

[54] A. Papayannis, D. Balis, V. Amiridis et al., "Measurements of Saharan dust aerosols over the eastern Mediterranean using elastic backscatter-Raman lidar, spectrophotometric and satellite observations in the frame of the EARLINET project," Atmospheric Chemistry and Physics, vol. 5, no. 8, pp. 20652079, 2005.

[55] A. Poupkou, D. Melas, I. Ziomas et al., "Simulated summertime regional ground-level ozone concentrations over Greece," Water, Air, \& Soil Pollution, vol. 196, no. 1-4, pp. 169-181, 2009.

[56] K. Markakis, A. Poupkou, D. Melas, and C. Zerefos, "A GIS based anthropogenic PM10 emission inventory for Greece," Atmospheric Pollution Research, vol. 1, no. 2, pp. 71-81, 2009. 

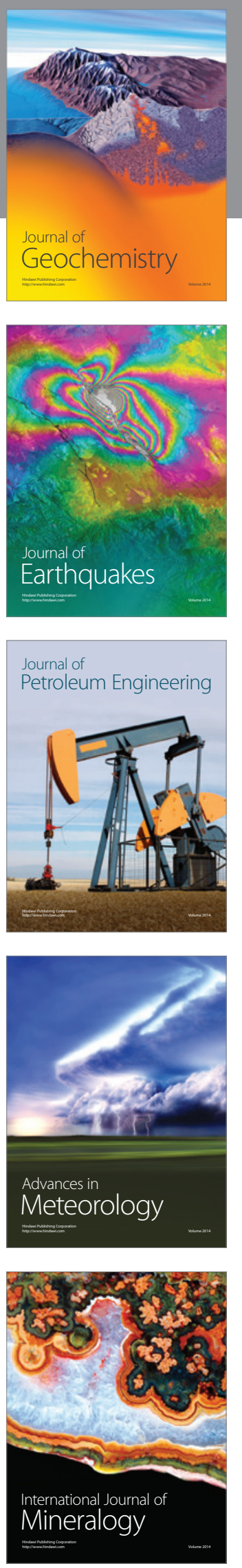
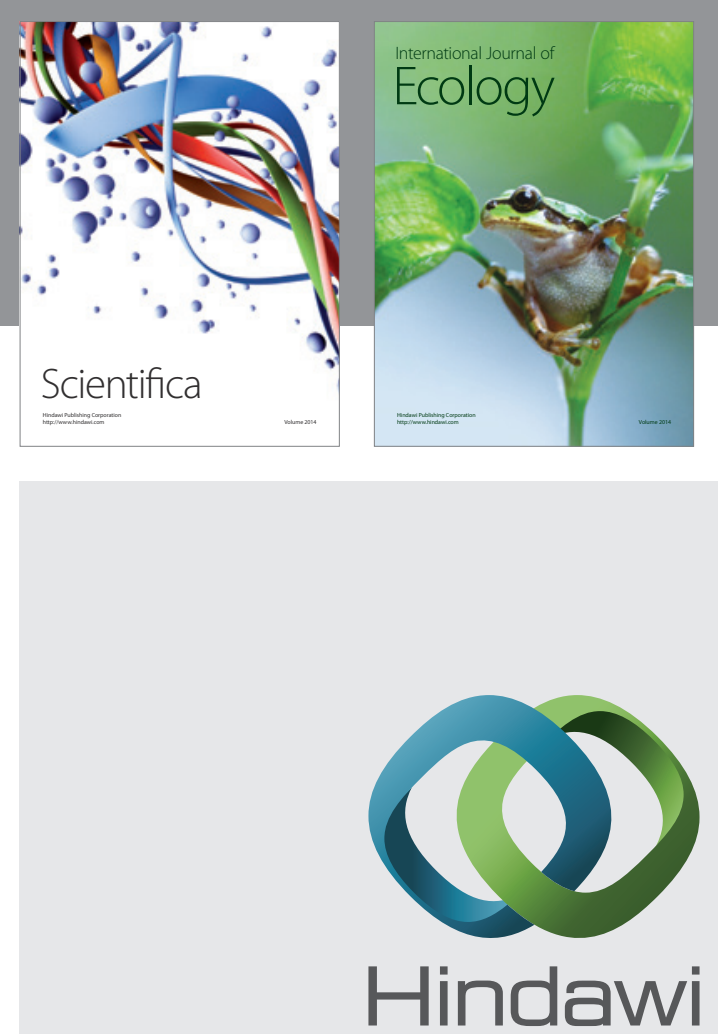

Submit your manuscripts at http://www.hindawi.com
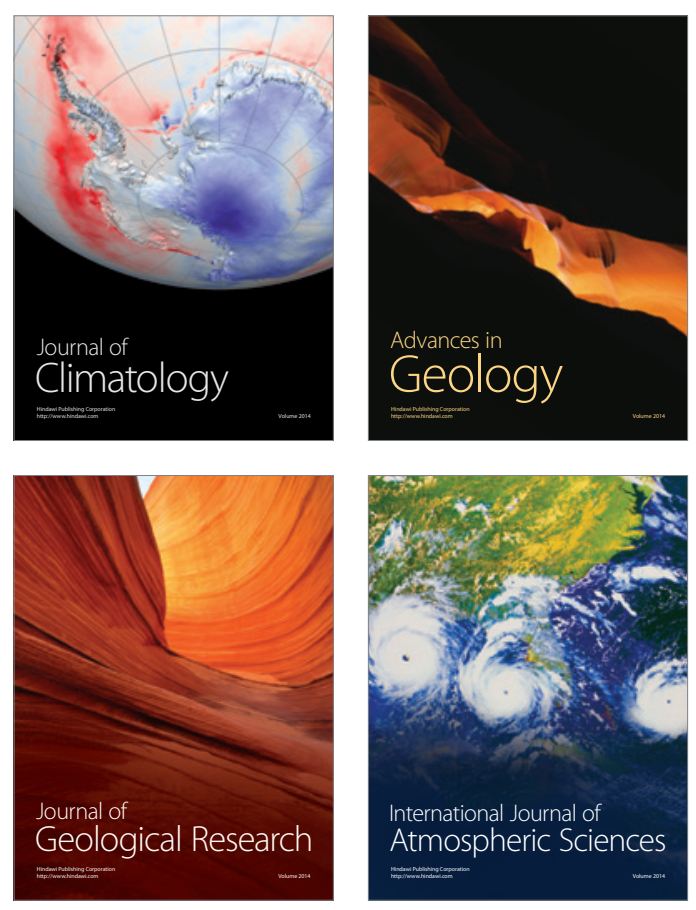
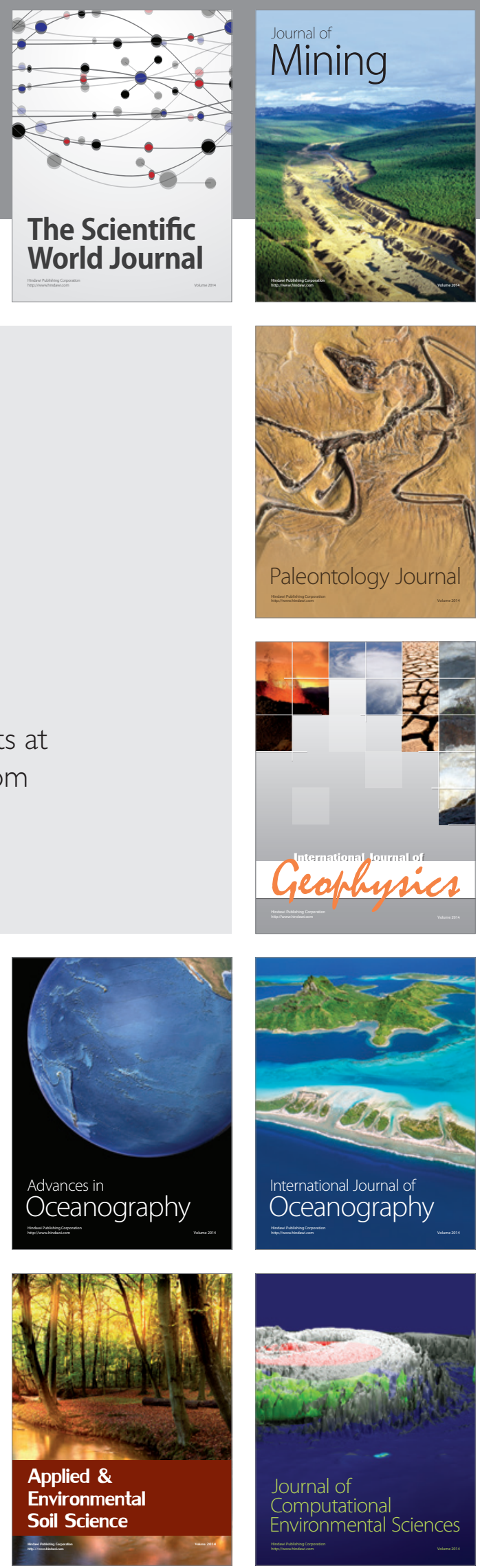